\title{
Investigation of the awareness of and demand for hospice care and attitudes towards life-sustaining treatment at the end of life among community residents in Hangzhou
}

Yanhong Xie ${ }^{1}$, Ying $X u^{2^{*}} \mathbb{D}$, Shulan Yang ${ }^{2}$, Jing Yan $^{3}$, Xiao Qing $\operatorname{Jin}^{3}$ and Caixia Liu

\begin{abstract}
Background: To understand the status of residents' awareness of and demand for hospice care services in Hangzhou and to provide a reference for promoting the formulation of hospice care-related policies in China.

Methods: A small cross-sectional survey of 519 adults aged over 40 years old living in the rural-urban fringe and urban area of Xihu District, Hangzhou City, was conducted using convenience sampling and a self-designed questionnaire. The measures assessed awareness of hospice care (13-item scale), attitudes towards life support therapy (3-item scale), and demand for hospice care services (9-item scale).

Results: The rate of awareness of hospice care among community residents was $50.30 \%$. A total of $51.0 \%$ of residents wanted only comfortable life-sustaining treatment at the end of their lives. The acceptance of hospice care was positively correlated with the degree of understanding $\left(x^{2}=18.382, P=0.001\right)$, and residents in the urban area were more likely to prefer hospice care than residents in the urban-rural fringe $\left(x^{2}=7.186, P=0.028\right)$. Elderly residents showed a stronger tendency to prefer comfortable life support therapy $\left(x^{2}=12.988, P<0.001\right)$. A total of $83.04 \%$ of the residents accepted the current necessity for hospice care to be provided in medical institutions. The preferred locations were professional hospice care institutions or general hospitals. A total of $93.64 \%$ of the residents agreed that the number of beds in hospice care wards should not exceed 2 . In addition, the residents could afford part of the out-of-pocket expenses for hospice care services, with the ability to pay under 200 yuan per day, and the improvement of facilities was expected.
\end{abstract}

Conclusions: To improve public awareness and acceptance of hospice care and promote healthy development in China, it is necessary to promote hospice care education for everyone.

Keywords: Hospice care, Cognition, End-of-life support therapy, Needs, Survey

*Correspondence: zjyyhlb2007@126.com

2Department of Nursing, Zhejiang Hospital, Hangzhou 310013, Zhejiang Province, China

Full list of author information is available at the end of the article

(c) The Author(s). 2020 Open Access This article is licensed under a Creative Commons Attribution 4.0 International License, which permits use, sharing, adaptation, distribution and reproduction in any medium or format, as long as you give appropriate credit to the original author(s) and the source, provide a link to the Creative Commons licence, and indicate if changes were made. The images or other third party material in this article are included in the article's Creative Commons licence, unless indicated otherwise in a credit line to the material. If material is not included in the article's Creative Commons licence and your intended use is not permitted by statutory regulation or exceeds the permitted use, you will need to obtain permission directly from the copyright holder. To view a copy of this licence, visit http://creativecommons.org/licenses/by/4.0/ The Creative Commons Public Domain Dedication waiver (http://creativecommons.org/publicdomain/zero/1.0/) applies to the data made available in this article, unless otherwise stated in a credit line to the data. 


\section{Background}

Hospice care began in the 1960s. According to the WHO definition, hospice care focuses on improving the quality of life of patients and their families who face problems associated with life-threatening illness through the prevention and relief of suffering by means of the early identification and treatment of other problems, including physical, psychosocial and spiritual problems [1]. Although hospice care was introduced to mainland China as early as 1988, its acceptance in Chinese society has been relatively slow. An important question for patients and their families is whether to continue or forego treatment at the end of life. One study showed that people with and without advance directives (ADs) had different preferences concerning different treatments [2]. Another study [3] showed that the choice of lifesustaining therapy was related to the patient's course and needs and that the decision to receive life-sustaining therapy differed according to differences in specific therapy measures.

With the aging of the population, the demand for care at the end of a disease is also increasing. According to an index system of the demand for hospice care (based on the burden caused by disease, dependency ratio of the elderly population, and speed of aging) [4], the objective demand in China is increasing.

At present, there are approximately 7.5 million deaths in China each year, and in approximately $80 \%$ of cases $(6$ million people), hospice care services are needed; however, the percentage of people receiving hospice care services in China lags significantly behind that in developed countries [5]. In October 2015, the Economist Intelligence Unit (EIU) released the Quality of Death Index for 2015; among 80 countries and regions in the world, Britain ranked first, and China ranked in the last 10 [6] This situation reflects the limited availability and low quality of palliative care in China. In recent years, with the promotion of the National Health Planning Commission, an increasing number of domestic scholars and policy makers have committed to "promoting the work of hospice care". According to incomplete statistics, hospice services in China have achieved good social benefits. In 2018, a total of 283,000 end-of-life patients were served, and the coverage rate of hospice care services reached $4.7 \%$ [7]. The government's policy support has just started, and residents' awareness and needs are important factors affecting government decisions. Understanding public perceptions about hospice may also help inform public education efforts to improve awareness of hospice as an option at the end of life [8]. Previous studies showed that $86 \%$ of adults living in the contiguous US had heard about hospice care [8], 76.3\% of respondents in Northern Ireland had heard the term palliative care [9], 93\% of community-dwelling older adults were familiar with term "hospice" [10], and $60 \%$ of
New York State residents associated hospice and palliative care with end-of-life care [11]. More than half (52.8\%) of the participants of one study (Korean residents aged 60 and older in Tampa and Orlando) reported that they had heard about hospice, and $73.6 \%$ of the sample expressed a willingness to use hospice [12]. A total of $82 \%$ of community-dwelling older adults in America strongly agreed/agreed that "hospice can make people feel better" [10]. (62.9\%) New York State residents were very likely to recommend this type of care to a loved one, while 224 (28\%) were somewhat likely [11].

Before providing services in any area, it is necessary to estimate the needs of local residents [13]. Therefore, our study was based in Zhejiang Province. The investigation of community residents in the Hangzhou metropolitan area and an integrated urban-rural community increases our understanding of the status of the awareness of and demand for hospice care among residents of different occupations and educational levels and provides an empirical basis for the dissemination of information about hospice care, the popularization and development of hospice care services and the formulation of related policy.

\section{Methods}

\section{Study design}

This study used a cross-sectional design and a sample of 519 older adults, who completed a questionnaire via an in-person interview. Before the data collection, written informed consent in Chinese was obtained from the participants. Research protocols were approved by the Zhejiang Hospital Ethics Institutional Review Board (IRB).

\section{Sample, participants, setting, and recruitment}

A convenience sampling method was used to select the participants. After IRB approval, participants were recruited from two sites, i.e., the urban-rural fringe and the metropolitan area of Hangzhou, from October 14 to November 8, 2018. The researchers defined pedestrians at the gate of the community as the survey objects. Pedestrians were invited to participate in the study via an announcement at the gate of the community and the distribution of flyers. After the announcement, adults who were interested in participating in the study were asked to provide their names and contact information by completing a sign-up sheet that would be passed around the dining hall or by contacting the researcher or research assistant to schedule an appointment. A total of 529 adults expressed an interest in participating in the study. Before scheduling an appointment for the interview, the participants were screened for eligibility for the study based on several criteria. One of the criteria concerned cognitive ability, which we assessed by using the 
Mini-Mental State Examination (MMSE) [14]. The MMSE covers the following seven aspects: time orientation, place orientation, immediate memory, attention and calculation, delayed memory, language, and visual space. For each of the 30 questions, 1 point is given for a correct answer, and 0 points are given for a wrong answer or unknown response; thus, the total score ranges from 0 to 30 points. The test scores are closely related to the level of education. The thresholds for normal cognition by education level have been defined as follows: illiterate, $>17$ points; primary school, $>20$ points; and junior high school and above, $>24$ points. Other inclusion criteria were healthy adults from different families without cognitive impairment who had lived in Hangzhou for more than 2 years and were over 40 years old. The exclusion criteria were as follows: medical workers with hearing or cognitive impairment who refused to participate in the survey. All the respondents provided informed consent and volunteered to participate in the survey. Among the 530 persons who indicated an interest in participating in the study, 6 participants did not meet the eligibility criteria (4 due to cognitive ability and 2 due to hearing ability). Ultimately, 524 persons agreed to participate and signed the consent form.

Before the survey was conducted, the questionnaire content instructions were formulated; the investigators were trained uniformly; and the purpose, significance and points for attention of the survey were explained with uniform guidance. The questionnaire was completed anonymously by participants and then checked and collected by the investigators on the spot. The questionnaires were administered via face-to-face interviews at a community neighborhood committee office. Each interview lasted approximately 15 to $20 \mathrm{~min}$, and respondents were offered a water bottle worth RMB 15-20 yuan as compensation. In this survey, 524 questionnaires were distributed. A total of 519 valid questionnaires were included in the analysis, while 5 questionnaires were considered invalid due to reasons such as the overselection of responses and missing responses; thus, the effective recovery rate was $99.05 \%$.

\section{Questionnaire}

A questionnaire on hospice care was designed by the project team based on the relevant literature $[15,16]$ and consultation with experts at home and abroad. The questionnaire consisted of four parts, including general information, hospice care cognition, acceptance of hospice care, and the demand for hospice care services. The general information questionnaire included 10 items covering information such as residence, gender, age, marital status, education level and monthly income. The second part assessed residents' cognitive attitudes towards hospice care, including the level of knowledge of hospice care (5 items), understanding (1 item), perceived objective and purpose of hospice care (2 items), treatment meaning ( 1 item), attitudes toward death acceptance and illness notification (3 items), and the perceived reason for the lack of the sufficient popularity of hospice therapy (1 item). The level of knowledge of hospice care was evaluated with the question "Have you heard about hospice care?", followed by 4 questions, each with one correct answer and several incorrect answers. If the respondent chose "have heard about it" and answered 3 or more questions correctly, he/she was considered to have a "better understanding". If the respondent chose "have heard about it" and answered 1-2 questions correctly, he/she was considered to have a "basic understanding". If the respondent chose "have never heard about it" or chose "have heard about it" and answered 0 questions correctly, he/she was considered to have "no understanding". The third part investigated community residents' acceptance of hospice care, including their willingness to sign a living will, their preference regarding medical decision-making, their willingness to accept hospice care services, etc. The fourth part assessed community residents' demand for hospice care services, including their choice of the hospice service location, the facilities and staffing of service organization, the charging standards, and family members' needs for physical and mental care during the patient's terminal stage. After the questionnaire was developed, experts were consulted. The validity of the questionnaire was 0.92 according to the Delphi expert consultation method. Twenty-five residents were selected for to complete the questionnaire two times, with the retest conducted 2 weeks after the first test. The correlation coefficient of the two sets of results was $0.906(P<0.05)$, which indicated that the questionnaire had good test-retest reliability.

Life-sustaining treatment is defined as any medical treatment that is intended to help someone or something to stay alive; that is, it supports or extends life [17]. Active life-sustaining treatment refers to the administration of all measures to sustain life, such as cardiopulmonary resuscitation (CPR), mechanical or artificial ventilation, clinically assisted nutrition and hydration, circulatory support, blood purification, or antibiotics. Comfortable life-sustaining treatment refers to life-sustaining measures aimed at alleviating the suffering of patients and meeting their physiological and psychological needs.

\section{Statistical analysis}

IBM SPSS vs. 25.0 software was used for statistical analysis. We calculated descriptive statistics for the entire sample. The chi-square test was used for categorical data analysis and group comparison. Continuous data were analyzed by the Kruskal-Wallis test. The association was 
considered statistically significant when $p$-values were less than 0.05 .

\section{Results}

\section{Characteristics of the participants}

A total of 519 people responded, for a $99.05 \%$ response rate. As shown in Table 1, there were 269 residents in the rural-urban fringe zone, accounting for $51.83 \%$ of the sample, and the remaining 250 were urban residents, accounting for $48.17 \%$ of the sample. Among the respondents, 227 were males (43.74\%), and 292 were females (56.26\%). Regarding their ages, 82 respondents were aged $40-49$, accounting for $15.80 \%$ of the sample; 108 were aged 50-59, accounting for 20.81\%; 171 were aged 60-69, accounting for $32.95 \%$; and 158 were aged $\geq 70$, accounting for $30.44 \%$. Regarding marital status, 65 (12.52\%) people had no spouse, and 454 (87.48\%) had spouses. In terms of education, 62 people had a primary

Table 1 Attitudes towards life-sustaining treatment at the end of life by participants' demographic characteristics $n$ (\%)

\begin{tabular}{|c|c|c|c|c|c|c|c|}
\hline \multirow[t]{3}{*}{ Project } & \multirow[t]{3}{*}{ Category } & \multicolumn{3}{|c|}{ Life-sustaining treatment attitudes at the end of life } & \multirow{3}{*}{$\begin{array}{l}\text { Total } \\
(n=519)\end{array}$} & \multirow[t]{3}{*}{$x_{\text {trend }} 2 / x^{2}$} & \multirow[t]{3}{*}{$P$} \\
\hline & & \multirow{2}{*}{$\begin{array}{l}\text { Active treatment } \\
(n=181)\end{array}$} & \multirow{2}{*}{$\begin{array}{l}\text { Comfortable support } \\
\text { treatment } \\
(n=265)\end{array}$} & \multirow{2}{*}{$\begin{array}{l}\text { No treatment } \\
\text { needed } \\
(n=73)\end{array}$} & & & \\
\hline & & & & & & & \\
\hline \multirow[t]{2}{*}{ Area of residence } & Rural-urban fringe & $108(40.15)$ & $124(46.10)$ & $37(13.75)$ & $269(51.83)$ & 7.186 & $0.028^{*}$ \\
\hline & Urban area & $73(29.20)$ & $141(56.40)$ & $36(14.40)$ & $250(48.17)$ & & \\
\hline \multirow[t]{2}{*}{ Gender } & Male & $79(34.80)$ & $116(51.10)$ & $32(14.10)$ & $227(43.74)$ & 0.001 & 0.975 \\
\hline & Female & $102(34.93)$ & $149(51.03)$ & $41(14.04)$ & $292(56.26)$ & & \\
\hline \multirow[t]{5}{*}{ Age } & $40 \sim 49$ & $34(41.46)$ & $42(51.22)$ & $6(7.32)$ & $82(15.80)$ & 12.988 & $<0.001 c$ \\
\hline & $50 \sim 59$ & $51(47.22)$ & $43(39.81)$ & $14(12.96)$ & $108(20.81)$ & & \\
\hline & $60 \sim 69$ & $52(30.41)$ & $94(54.97)$ & $25(14.62)$ & $171(32.95)$ & & \\
\hline & $70 \sim 79$ & $34(30.09)$ & $63(55.75)$ & $16(14.16)$ & $113(21.77)$ & & \\
\hline & $>80$ & $10(22.22)$ & $23(51.11)$ & $12(26.67)$ & $45(8.67)$ & & \\
\hline \multirow[t]{2}{*}{ Marital status } & Single & $22(33.85)$ & $34(52.31)$ & $9(13.85)$ & $65(12.52)$ & 0.048 & 0.976 \\
\hline & Married & 159 (35.02) & $231(50.88)$ & $64(14.10)$ & $454(87.48)$ & & \\
\hline \multirow[t]{4}{*}{ Education level } & Primary school and below & $28(45.16)$ & $25(40.32)$ & $9(14.52)$ & $62(11.94)$ & 2.677 & 0.102 \\
\hline & Junior & $52(34.90)$ & $73(48.99)$ & $24(16.11)$ & $149(28.71)$ & & \\
\hline & $\begin{array}{l}\text { High School/Technical } \\
\text { School }\end{array}$ & $52(35.37)$ & $72(48.98)$ & $23(15.65)$ & $147(28.32)$ & & \\
\hline & Junior college or above & $60(28.85)$ & $123(59.15)$ & $25(12.02)$ & $208(40.08)$ & & \\
\hline \multirow{5}{*}{$\begin{array}{l}\text { Monthly after-tax } \\
\text { income (RMB) }\end{array}$} & No income & $14(51.85)$ & $9(33.33)$ & $4(14.81)$ & $27(5.20)$ & 1.753 & 0.185 \\
\hline & $1 \sim 3000$ & 39 (39.39) & $45(45.45)$ & $15(15.15)$ & 99 (19.08) & & \\
\hline & $3001 \sim 5000$ & $70(33.02)$ & $110(51.89)$ & $32(15.09)$ & $212(40.85)$ & & \\
\hline & $5001 \sim 10,000$ & $51(34.00)$ & $83(55.33)$ & $16(10.67)$ & $150(28.90)$ & & \\
\hline & $>10,000$ & $7(22.58)$ & $18(58.06)$ & $6(19.35)$ & $31(5.97)$ & & \\
\hline \multirow[t]{4}{*}{ Medical insurance } & Out of pocket & $10(34.48)$ & $12(41.38)$ & $7(24.14)$ & $29(5.59)$ & 4.868 & 0.561 \\
\hline & $\begin{array}{l}\text { New rural cooperative } \\
\text { medical service }\end{array}$ & $32(42.11)$ & $35(46.05)$ & $9(11.84)$ & $76(14.64)$ & & \\
\hline & $\begin{array}{l}\text { Basic medical insurance } \\
\text { for urban residents }\end{array}$ & $42(34.15)$ & $64(52.03)$ & $17(13.82)$ & $123(23.70)$ & & \\
\hline & $\begin{array}{l}\text { Basic medical insurance } \\
\text { for urban workers }\end{array}$ & $97(33.33)$ & $154(52.92)$ & $40(13.75)$ & $291(56.07)$ & & \\
\hline \multirow[t]{2}{*}{ Religious beliefs } & No & $27(7.40)$ & $148(40.55)$ & $190(52.05)$ & $365(70.33)$ & $1.759^{\mathrm{a}}$ & 0.079 \\
\hline & Yes & $16(10.40)$ & $70(45.50)$ & $68(44.20)$ & $154(29.67)$ & & \\
\hline \multirow{2}{*}{$\begin{array}{l}\text { Experience of the death } \\
\text { of an immediately } \\
\text { family member }\end{array}$} & Yes & $127(34.79)$ & $190(52.05)$ & $48(13.15)$ & $365(70.33)$ & 0.973 & 0.615 \\
\hline & No & $54(35.06)$ & $75(48.70)$ & $25(16.23)$ & $154(29.67)$ & & \\
\hline \multirow{2}{*}{$\begin{array}{l}\text { Experience of caring for } \\
\text { dying patients }\end{array}$} & Yes & $95(37.55)$ & $127(50.20)$ & $31(12.25)$ & $253(48.75)$ & 2.237 & 0.327 \\
\hline & No & $86(32.33)$ & $138(51.88)$ & 42 (15.79) & $266(51.25)$ & & \\
\hline
\end{tabular}


school or below education level, accounting for 11.95\% of the sample; 100 had a junior high school above education level, accounting for 19.27\%; 149 had a senior high school or technical secondary school educational level, accounting for 28.71\%; and 208 had higher education, accounting for $40.08 \%$. Regarding income, 27 people had no monthly income, accounting for $5.20 \%$; 99 people earned 1-3000 yuan, accounting for 19.08\%; 212 people earned 3001-5000 yuan, accounting for 40.85\%; 150 people earned 5001-10,000 yuan, accounting for $28.90 \%$; and 31 earned more than 10,000 yuan, accounting for $5.97 \%$. In regard to the medical system, 76 people had new rural cooperative medical insurance, accounting for 14.64\%; 123 people had basic medical insurance for urban residents, accounting for 23.70\%; 291 people had basic medical insurance for urban workers and residents, accounting for $56.07 \%$; and 29 people had no medical insurance and paid out of pocket, accounting for $5.59 \%$. In regard to religious beliefs, 365 people had no religious beliefs, accounting for $70.33 \%$, and 154 people had religious beliefs, accounting for $29.67 \%$. Moreover, 365 people had experience with death of immediate relatives, accounting for $70.33 \%$. In addition, 253 people had experience caring for dying patients, accounting for $48.75 \%$.

\section{Current situation of community residents' awareness of hospice care}

The survey found that $8.29 \%$ of the residents reported better knowledge of hospice care and that $42.00 \%$ reported a basic knowledge; that is, $50.30 \%$ knew about hospice care. A total of $46.82 \%$ did not know about hospice care, and $2.89 \%$ did not want to know about hospice care and believed there was a taboo surrounding it. As we can see in Table 2.

\section{Community residents' attitudes towards life-sustaining treatment at the end of life}

In addition, $34.9 \%$ of the residents preferred active lifesustaining treatment, $51.0 \%$ of the residents wanted only noninvasive, comfortable life-sustaining treatment, and $14.1 \%$ of the residents did not think they needed any life-sustaining treatment. As we can see Table 2.
The relationship between community residents' awareness of hospice care and their attitudes towards life support therapy

The chi-square results showed that the awareness of hospice therapy and nursing care was related to the choice of life support therapy. The greater the patient's understanding of hospice therapy and nursing care, the more inclined the patient was to choose comfortable life support therapy $\left(\mathrm{x}^{2}=18.382, P=0.001\right)$. The results are shown in Table 2.

Attitudes towards life-sustaining treatment at the end of life by participants' demographic characteristics

According to Table 1, there were significant differences in the demand for life support therapy among residents from different areas of residence and of different ages $(P<0.05)$, while there were no differences based on other categories such as gender, marital status, education, monthly after-tax income, medical insurance type, religious beliefs, experience of the death of immediate relatives and experience of the care of dying patients $(P>0.05)$. Furthermore, based on a comparison of the percentage differences, residents of the metropolitan area were more likely to prefer noninvasive and comfortable life-sustaining treatment $\left(\mathrm{x}^{2}=7.186, P<0.05\right)$ residents of the urban-rural fringe. In addition, the chisquare for trend showed that age was related to the choice of life support therapy. The older the patient's age, the more choice likely he or she was to indicate a preference for comfortable life support therapy or no need for life support therapy $\left(\mathrm{x}^{2}\right.$ trend $\left.=12.988, P<0.01\right)$.

\section{Community demand for hospice care services}

According to Tables 3 and 4, community residents' main expectations of hospice care were reduced discomfort symptoms (such as pain and nausea) and side effects of drugs (75.53\%), medical help (60.31\%) and companionship $(50.1 \%)$. A total of $83.04 \%$ of the community residents believed that it was necessary for medical institutions to provide hospice care. A total of 49.71 and $44.32 \%$ of the residents wanted to receive hospice care services in professional hospice care institutions or general hospitals, respectively, and $39.69 \%$ of the residents

Table 2 The relationship between community residents' awareness of hospice care and their attitudes towards life-sustaining treatment

\begin{tabular}{|c|c|c|c|c|c|c|c|}
\hline \multirow[t]{2}{*}{ Project } & \multirow[t]{2}{*}{ Category } & \multicolumn{3}{|c|}{ Life-sustaining treatment attitudes at the end of life } & \multirow{2}{*}{$\begin{array}{l}\text { Total } \\
(n=519)\end{array}$} & \multirow[t]{2}{*}{$x^{2}$} & \multirow[t]{2}{*}{$P$} \\
\hline & & $\begin{array}{l}\text { Active treatment } \\
(n=181)\end{array}$ & $\begin{array}{l}\text { Comfortable support } \\
\text { treatment }(n=265)\end{array}$ & $\begin{array}{l}\text { No treatment } \\
\text { needed }(n=73)\end{array}$ & & & \\
\hline \multirow{3}{*}{$\begin{array}{l}\text { Awareness of } \\
\text { hospice care }\end{array}$} & Better understanding & $11(25.58)$ & $29(67.44)$ & $3(6.98)$ & $43(8.29)$ & \multirow[t]{3}{*}{18.382} & \multirow[t]{3}{*}{$0.001^{* *}$} \\
\hline & Basic understanding & $61(27.98)$ & $127(58.26)$ & $30(13.76)$ & $218(42.00)$ & & \\
\hline & No understanding & $109(42.24)$ & $109(42.25)$ & $40(15.50)$ & $258(49.71)$ & & \\
\hline \multicolumn{2}{|l|}{ Total } & $181(34.88)$ & $265(51.05)$ & 73 (14.06) & $519(100.00)$ & & \\
\hline
\end{tabular}


Table 3 Community demand for hospice care services, n (\%)

\begin{tabular}{|c|c|c|c|c|c|c|c|c|c|c|c|c|}
\hline \multicolumn{4}{|c|}{$\begin{array}{l}\text { Service expectations (multiple } \\
\text { choice) }\end{array}$} & \multicolumn{3}{|c|}{ Preferred location (multiple choice) } & \multicolumn{3}{|c|}{$\begin{array}{l}\text { Expectations about number of } \\
\text { beds per room }\end{array}$} & \multicolumn{3}{|c|}{$\begin{array}{l}\text { Out-of-pocket costs } \\
\text { (RMB/month) }\end{array}$} \\
\hline & Expectation & Frequency & Percentage & Location & Frequency & $\overline{\text { Percentage }}$ & $\begin{array}{l}\text { Number of } \\
\text { beds }\end{array}$ & Frequency & $\overline{\text { Percentage }}$ & Cost & Frequency & $\overline{\text { Percentage }}$ \\
\hline 1 & $\begin{array}{l}\text { Reduced } \\
\text { discomfort }\end{array}$ & 392 & 75.53 & $\begin{array}{l}\text { Professional } \\
\text { hospice care } \\
\text { institutions }\end{array}$ & 258 & 49.71 & One & 234 & 45.09 & $<200$ & 324 & 62.43 \\
\hline 2 & $\begin{array}{l}\text { Medical } \\
\text { help }\end{array}$ & 313 & 60.31 & $\begin{array}{l}\text { General } \\
\text { hospital }\end{array}$ & 230 & 44.32 & Two & 252 & 48.55 & $\begin{array}{l}200 \sim \\
400\end{array}$ & 138 & 26.59 \\
\hline 3 & Company & 260 & 50.10 & Home & 206 & 39.69 & Three & 27 & 5.2 & $\begin{array}{l}400 \sim \\
600\end{array}$ & 32 & 6.17 \\
\hline 4 & $\begin{array}{l}\text { Assistance in } \\
\text { completing } \\
\text { a will }\end{array}$ & 214 & 41.23 & $\begin{array}{l}\text { Pension } \\
\text { agency }\end{array}$ & 205 & 39.5 & Other & 6 & 1.16 & $\begin{array}{l}600 \sim \\
800\end{array}$ & 12 & 2.31 \\
\hline 5 & $\begin{array}{l}\text { Funeral } \\
\text { preparations }\end{array}$ & 177 & 34.1 & $\begin{array}{l}\text { Community } \\
\text { health center }\end{array}$ & 114 & 21.97 & & & & $>800$ & 13 & 2.50 \\
\hline
\end{tabular}

wanted to receive hospice care services at home. The proportions of residents who were willing to accept hospice care in nursing institutions or community health centers were 39.50 and $21.97 \%$, respectively. A total of $62.43 \%$ of the residents desired the average daily out-ofpocket costs of hospice care service to be less than 200 yuan, and more than $80 \%$ of the residents $(87.48 \%)$ believed that hospice care drugs and services should be included in medical insurance reimbursement. A total of $85.55 \%$ of the residents thought that the hospital should establish a separate hospice ward, $88.82 \%$ of the residents agreed that the hospice ward should have a family waiting room, $82.27 \%$ of the residents thought that the hospice ward should have special equipment (automatic bathing machine, automatic turning over bed, etc.), and $83.04 \%$ of the residents thought that the hospice ward should have a farewell room/caring room.

\section{Discussion}

This study aimed to understand the status of residents' awareness of and demand for hospice care services in Hangzhou and to provide a reference for promoting the formulation of hospice care-related policies in China. The results showed that the rate of awareness of hospice care among community residents was $50.30 \%$. A total of $51.1 \%$ of residents desired comfortable life-sustaining treatment at the end of their lives. The acceptance of hospice care was positively correlated with degree of understanding. Residents of metropolitan areas were more likely to prefer hospice care than residents of urban-rural areas, and elderly residents showed a stronger preference for comfortable life support therapy. A total of $83.04 \%$ of the residents accepted the current necessity for hospice care to be provided in medical institutions, and the preferred locations for hospice care were professional hospice care institutions or general hospitals. A total of $93.64 \%$ of the residents agreed that the number of beds in hospice care wards should not exceed 2. In addition, the residents could afford to pay part, i.e., below 200 yuan per day, of the out-of-pocket expenses for hospice care services, and the improvement of facilities was expected.

Community residents have low awareness of hospice care The survey showed that the rate of awareness of hospice care among community residents was $50.30 \%$, which indicated that residents had a certain degree of understanding of hospice care. This result was similar to that of Tang Zheng yan's survey of community residents in Xi'an (51.7\%) and slightly higher than that reported in Sweden (43\%) [18]. However, there is a large gap between the observed public awareness rate and those of advanced developed countries and regions in the world, such as Northern Ireland (the UK), at $81.0 \%$ [9] and the contiguous United States among the general population (86\%) [8] and Hispanics (56\%) [19] this gap is mainly

Table 4 Other resident needs for hospice care services, n (\%)

\begin{tabular}{lll}
\hline Need (multiple choice) & Frequency & Percentage \\
\hline Hospice care is now necessary in medical institutions & 431 & 83.04 \\
Hospice care drugs and services should be covered by medical insurance reimbursement & 454 & 87.48 \\
Hospice patients should be accompanied by family members & 461 & 48.82 \\
Special equipment is needed (automatic bathing machine, automatic turning bed, etc.) & 431 & 82.27 \\
A farewell room/care room should be provided & 83.04 \\
\hline
\end{tabular}


related to the cultural background of our country. Influenced by our traditional culture, most people find talking about death to be taboo and generally still do not accept the concept of a "good death". Therefore, the acceptance of hospice care services in Chinese society is relatively low. Until now, most medical resources in the general environment have been accepted slowly. These resources all focus on curative treatment. Due to the refusal to discuss topics such as death, China has been slow to embrace the concept of palliative care, in large part due to the lack of life education. In addition, the lack of support at the national level for law and policy on hospice care; the lack of positive propaganda and guidance from public opinion and the media on hospice care concepts, even in medical colleges and universities; and the lack of propaganda and education on death, hospice care and hospice care have led to a lack of understanding of hospice care among Chinese people. In addition, because China has adhered to the tradition of filial piety since ancient times and because of the tenets of filial piety, people think it is in violation of this principle to send elderly people to hospice care institutions, which invisibly hinders acceptance of the concept of hospice care.

\section{Community residents have demand for hospice care}

Palliative and hospice care have been associated with improved patient symptom control and quality of life [20] as well as increased satisfaction with care. According to the present survey, $34.9 \%$ of the residents needed active lifesustaining treatment at the end of their lives. This may be related to the importance of the culture of filial piety in China. According to the available literature, a combination of race, individual characteristics, attitudes, beliefs, and behaviors contribute to a person's preference for hospice [21]. When patients lose their decision-making ability, many family members fail to consider the advantages and disadvantages of life-sustaining treatment at the end of patients' lives and instead hold onto the idea of saving the patient's life, making rescue efforts ineffective and leading to a refusal to stop life-sustaining until the patient is exhausted. The proportion of residents willing to accept noninvasive and comfortable life-sustaining treatment was $51.1 \%$, which was similar to the residents' rate of awareness of hospice care (50.30\%). Residents have demands or potential demands for hospice care services, and residents hope that hospice care services will mainly reduce their discomfort symptoms (75.53\%) and provide medical help (60.31\%) and companionship (50.10\%).

\section{Improving the understanding of hospice is conducive to the development of hospice care}

Despite the documented benefits of palliative and hospice care in improving patients' quality of life, these services remain underutilized. Multiple factors limit the utilization of these services, including patients' and caregivers' lack of knowledge and misperceptions [11]. The evidence shows that public awareness campaigns can improve the awareness of palliative care and probably improve the quality of care [22]. The statistical analysis showed that the level of understanding of hospice care affected the acceptance of hospice care. The more people knew about hospice care, the more likely they were to accept hospice care, which was consistent with the results of Cagle et al. [8]. Recent research [23] has observed that the public has poor knowledge and awareness about hospice care, and several misperceptions exist; these findings have remained constant over time despite growth in the field of hospice care, which highlights the strong need for focused educational interventions. Therefore, in the future, we should pay attention to the dissemination of hospice care knowledge and propaganda to allow more residents to learn about hospice care, which would be conducive to the development of hospice care.

\section{Different groups have different demands for hospice care} The study found that residents of metropolitan areas were more likely than those in the rural-urban fringe to prefer noninvasive and comfortable life support therapy. Respondents who were more educated were also more likely to be more knowledgeable about hospice [8]. This finding may be due to the relatively limited exposure to information about hospice among residents among residents of the rural-urban fringe, who hold relatively conservative views. Urban residents could more easily access information through newspapers, social networks, television and other channels and thus more readily accepted new ideas. They payed attention to eugenics but also had begun to pay attention to a 'good death'. In addition, older people tended to choose comfortable life support therapy, which was consistent with the findings of Zhang et al. [24] and Cagle et al. [8]. Similarly, a previous research [25] result showed that older adults with higher education levels have greater odds of agreeing that advance directives are necessary. This may be because elderly people have experienced more deaths and have greater awareness that ineffective medical treatment not only increases the financial burden of their children but also may not improve their quality of life. Therefore, elderly people had a higher acceptance rate of hospice care.

Hospice care in professional hospice care institutions and general hospitals is more acceptable than that offered in other locations

Dying in a preferred place is important for achieving a good death for both the patient and his/her family. Nearly half of the respondents hoped to receive hospice care in professional hospice institutions or general 
hospitals, while home (39.69\%) was the third choice. This was inconsistent with the finding on the preferred place for hospice care in Northern Ireland (UK), which was family residence (61\%) [9], and in Japan, where residents generally preferred hospice care at home (64\%) [26]. The survey showed that approximately $70 \%$ of respondents chose home as the preferred place for EOL care and/or death [18]. Home was the most preferred place of death (56\%), and the hospital was least preferred (25\%) [27]. The reasons may be related to the lack of knowledge and awareness of hospice care among Chinese residents, the lack of a hospice care system and the singularity of hospice care services in China. In addition, Chinese people have more taboos about dying at home. In China, residents can obtain effective pain relief measures in hospitals, whereas home care is very limited.

A total of $83.04 \%$ of the residents believed that it was necessary for medical institutions to provide hospice care, which indicated that residents still had relative trust in hospitals. The reasons were as follows. (1) Residents believed that professional hospice and general hospitals had the necessary basic conditions and relatively mature care technology to provide hospice care, in contrast to community hospitals and pension institutions, and that the caregivers were more professional. The patients also felt more comfortable staying in hospitals. With families becoming increasingly younger and the increasing pressure of social competition, many families feel powerless or confused when their elderly relatives are dying. Therefore, it is necessary for professional hospice care institutions or general hospitals to provide hospice care to relieve the suffering of patients and reduce the burden of family members. It can be seen that in China, general hospitals will assume the main responsibility of hospice care for dying patients, and the promotion of hospice care needs to start from general hospitals.

\section{Other demands of residents for hospice care}

According to the survey, the majority of residents (93.64\%) agreed that the number of beds in the hospice ward should not exceed 2. With the development of China's economy, residents' expectations of quality of life are increasing. The past large-scale ward model of 4-6 people is not suitable given the current development of residents' demands for hospice care. The affordability of hospice care cannot be separated from the coverage of universal health insurance. Countries with high death quality, such as Britain, Singapore and Japan, pay for hospice care services through universal health insurance. The results of this survey showed that $62.43 \%$ of the residents in the studied province wanted to take care of their own expenses for hospice care services, and more than $80 \%$ of them preferred to pay less than 200 yuan/ day. Medicines and services should be included in medical insurance reimbursement, which suggests that hospice care should be gradually included in the scope of basic medical security in China. In addition, more than $80 \%$ of the residents hoped that the hospice and nursing institutions would have single rooms that allowed family to accompany the patient and farewell rooms/caring rooms. They also hoped that hospice and nursing institutions would be equipped with special equipment (such as automatic bathing machines and automatic patient-turning beds). This suggests that our country still needs to make efforts to improve the facilities of hospice and nursing service institutions.

\section{Conclusions}

This study also has several potential limitations. This study used a convenience sampling method with a small sample size, which limits the generalizability of the results. People who did not volunteer to participate in the study might have had different characteristics, such as poor health and mental health status, than the included participants and thus might have had different perspectives on awareness and demand for hospice care. Future studies should employ a probability sampling method with a larger sample size to enhance generalizability. Second, the study population was over 40 years old, which potentially limits the generalizability of our findings to all adults. Finally, this study had a relatively small sample, therefore may limit broader inferences from the results. In the future, the geographical scope of the area from which respondents are sampled needs to be further expanded.

This study investigated the current situation of residents' awareness of and demand for hospice care in Hangzhou. More than $50 \%$ of the residents knew about hospice care, and more than $50 \%$ of the residents were willing to receive hospice care at the end of their lives. Moreover, the greater residents' understanding of hospice care was, the greater their acceptance; in addition, residents of the metropolitan area and elderly residents were more likely to choose comfortable life-sustaining treatment. Residents preferred hospice care to be provided in professional hospice care institutions and general hospitals. Most residents agreed that the number of beds in hospice care wards should not exceed 2 . In addition, residents hoped that the out-of-pocket costs of hospice care services would be less than 200 yuan/day, and they expected the facilities of hospice and nursing service institutions to be improved. Therefore, it is necessary to provide hospice care education for everyone to improve public awareness and acceptance of hospice care in China. The results of the survey provide a reference for promoting the formulation of relevant policies on hospice care in China. 


\section{Abbreviations}

EIU: Economist Intelligence Unit

\section{Acknowledgements}

Thanks to Wang Xianyi, the director of the Civil Affairs Research Center of Zhejiang Provincial Civil Affairs Department, for his strong support in this research.

\section{Authors' contributions}

Conceptualization: JY, YX, JXQ, and YHX. Formal analysis: YHX and SLY. Investigation: YHX, SLY, YX, and CXL. Methodology: JY and YHX. Project administration: JY, YX, XQJ, and YHX. Resources: JY, YHX, YX, and XQJ. Validation: SLY, YJ, and YX. Writing original draft: YHX. All authors read and approved the final manuscript.

\section{Funding}

This work was supported by Zhejiang Civil Affairs Development Promotion Association and Zhejiang Provincial Medicine and Health Technology Project (grant number 2019KY003).

The funder had no role in study design, data collection, analysis and interpretation or writing the manuscript.

\section{Availability of data and materials}

The datasets used and/or analyzed during the current study are available from the corresponding author from bona fide researchers with appropriate ethical clearance.

\section{Ethics approval and consent to participate}

This research project was reviewed and approved by the Medical Ethics Committee of Zhejiang Hospital. All participants provided written, informed consent.

\section{Consent for publication}

Not applicable.

\section{Competing interests}

The authors declare that they have no competing interests.

\section{Author details}

1Department of Geriatrics, Zhejiang Hospital, Hangzhou 310013, Zhejiang

Province, China. ${ }^{2}$ Department of Nursing, Zhejiang Hospital, Hangzhou

310013, Zhejiang Province, China. ${ }^{3}$ Zhejiang Hospital, Hangzhou 310013,

Zhejiang Province, China.

Received: 17 April 2020 Accepted: 5 August 2020

Published online: 17 August 2020

\section{References}

1. World Health Organization. WHO definition of palliative care. https://www. who.int/cancer/palliative/definition/en/. Accessed 3 Apr 2020.

2. van Wijmen MPS, Pasman HRW, Widdershoven GAM, Onwuteaka-Philipsen $\mathrm{BD}$. Continuing or forgoing treatment at the end of life? Preferences of the general public and people with an advance directive. J Med Ethics. 2015:41: 599-606.

3. Hunag W, Han D. Investigation and reflection on public willingness of advance medical directives in Guangzhou. Chin J Med Ethics. 2018;7:913-8.

4. Suli S. Discussions on the related issues of pre-natal testimony. Chin's Health Leg Syst. 2014;2:7-11.

5. Di S, Zhang J, Zhang X. History, development and prospect of hospice care. Med Res Educ. 2018;1:7-12.

6. Economist Intelligence Unite. The $\mathbf{2 0 1 5}$ quality of death index ranking palliative care across the world; 2015. http://www.lienfoundation.org/sites/default/files/2 015\%20Quality\%20of\%20Death\%20Report.pdf. Accessed 5 Oct 2015.

7. Dong $X$, Xinhua News Agency. The rapid development of nationwide hospiceity nursing services has served 283,000 patients last year; 2019 https://www.sohu.com/a/318334233 267106. Accessed 4 Apr 2020.

8. Cagle JG, Van Dussen DJ, Culler KL, Carrion I, Hong S, Guralnik J, et al. Knowledge about hospice. Am J Hosp Palliat Med. 2016:33:27-33.

9. Mcllfatrick S, Hasson F, McLaughlin D, Johnston G, Roulston A, Rutherford L, et al. Public awareness and attitudes toward palliative care in Northern Ireland. BMC Palliat Care. 2013;12:34.
10. Manu E, Mack-Biggs TL, Vitale CA, Galecki A, Moore T, Montagnini M. Perceptions and attitudes about hospice and palliative care among community-dwelling older adults. Am J Hosp Palliat Med. 2013;30:153-61.

11. Shalev A, Phongtankuel V, Kozlov E, Shen MJ, Adelman RD, Reid MC. Awareness and misperceptions of hospice and palliative care: a populationbased survey study. Am J Hosp Palliat Care. 2018;35:431-9.

12. Jang Y, Chiriboga DA, Allen JY, Kwak J, Haley WE. Willingness of older Korean-American adults to use hospice. J Am Geriatr Soc. 2010;58:352-6.

13. Daya AP, Sarkar S, Kar SS. Estimation of palliative care need in the urban community of Puducherry. Indian J Palliat Care. 2017;23:81-7.

14. Shahid A, Wilkinson K, Marcu S, Shapiro CM. Mini-mental state examination (MMSE). In: Shahid A, Wilkinson K, Marcu S, Shapiro C, editors. Stop, that and one hundred other sleep scales. New York: Springer; 2011. p. 223-4.

15. Tang ST, Liu TW, Chow JM, Chiu CF, Hsu C, Liu LN, et al. Gap in the intensity of end-of-life care between younger and older taiwanese adult cancer patients may not reflect younger patients' preferences. J Cancer Res Pract. 2015;2:195-204.

16. Chang $\mathrm{HLCL}$. Exploring the cognition of elderly patients and their families in the intensive care unit of a medical center in Central China to the preestablished medical exploring the cognition of elderly patients and their families in the intensive care unit of a medical center in Central China to the pre-established medical instructions. Taiwan J Geriatr Gerontol. 2016;1: 50-65.

17. Merriam-Webster. Life-sustaining. https://www.merriam-webster.com/ dictionary/life-sustaining. Accessed 27 Jun.

18. Westerlund C, Tishelman C, Benkel I, Fürst CJ, Molander U, Rasmussen BH, et al. Public awareness of palliative care in Sweden. Scand J Public Health. 2018;46:478-87.

19. Carrion IV, Cagle JG, Van Dussen DJ, Culler KL, Hong S. Knowledge about hospice care and beliefs about pain management. Am J Hosp Palliat Med. 2015;32:647-53.

20. Zimmermann C, Swami N, Krzyzanowska M, Hannon B, Leighl N, Oza A et al. Early palliative care for patients with advanced cancer: a clusterrandomised controlled trial. Lancet. 2014;383:1721-30.

21. Cagle JG, LaMantia MA, Williams SW, Pek J, Edwards LJ. Predictors of preference for hospice care among diverse older adults. Am J Hosp Palliat Care. 2016:33:574-84.

22. Seymour J. The impact of public health awareness campaigns on the awareness and quality of palliative care. J Palliat Med. 2018;21:S30-S6.

23. Patel $P$, Lyons L. Examining the knowledge, awareness, and perceptions of palliative care in the general public over time: a scoping literature review. Am J Hosp Palliat Med. 2020;37:481-7.

24. Zhang S, Yin C, Yu T. Investigation and analysis on the cognition and attitude of urban residents to peaceful death. Chin Med Ethics. 2016:3:458-60.

25. Lee JE, Shin DW, Son KY, Park HJ, Lim JY, Song MS, et al. Factors influencing attitudes toward advance directives in Korean older adults. Arch Gerontol Geriatr. 2018;74:155-61.

26. Nishie H, Mizobuchi S, Suzuki E, Sato K, Toda Y, Matsuoka J, et al. Living will interest and preferred end-of-life care and death locations among Japanese adults 50 and over: a population-based survey. Acta Med Okayama. 2014;68: 339-48.

27. Higginson IJ, Daveson BA, Morrison RS, Yi D, Meier D, Smith M, et al. Social and clinical determinants of preferences and their achievement at the end of life: prospective cohort study of older adults receiving palliative care in three countries. BMC Geriatr. 2017:17:271.

\section{Publisher's Note}

Springer Nature remains neutral with regard to jurisdictional claims in published maps and institutional affiliations. 